\title{
Memorias sonoras que acumula el cuerpo al viajar por debajo de la tierra ${ }^{1}$
}

\author{
Ximena Alarcón \\ RITMO Centre for Interdisciplinary Studies in Rhythm, Time and Motion \\ Department of Musicology, University of Oslo \\ x.a.diaz@imv.uio.no
}

\section{Resumen}

A partir de las memorias sonoras de los pasajeros del transporte público subterráneo en Londres, México y París, creé el sitio interactivo en internet Sounding Underground. Esta interfaz articula estructural y aleatoriamente la esencia de una memoria sónica subterránea. Partiendo de la propuesta de Pauline Oliveros de escuchar profundamente como una práctica que incluye todas las sensaciones corporales, he considerado los sistemas físicos de transporte subterráneo y el entorno sonoro virtual que he creado, como "utopías" y "heterotopías" del sueño humano de movilidad. En este documento, sugiero que Sounding Underground actúa como una interfaz incorpórea que transforma potencialmente la memoria corporal, involucrando sentimientos asociados a lo "sublime", como un legado de la Revolución Industrial.

Palabras clave: espacio sonoro interactivo en red, metro subterráneo, memoria corporal, escucha profunda, movilidad.

\section{Embodied Sonic Memories of Commuting Underground}

\begin{abstract}
From commuters' listening memories of underground public transportation in London, Mexico and Paris, I created the online interactive environment Sounding Underground. This interface structurally and randomly articulates the essence of an underground sonic memory. Departing from Pauline Oliveros' perspective of listening deeply as an embodied practice, I have considered both the physical underground transportation systems and the created virtual sonic environment as "utopias" and "heterotopias", from the human dream of mobility. In this paper, I am suggesting that Sounding Underground acts as a disembodied interface that potentially transforms body memories, involving "sublimity", left as a legacy of Industrial Revolution.
\end{abstract}

Keywords: online sonic environment, underground, embodiment, memories, deep listening, mobility.

1. Este material es una traducción del original en inglés que se publicará en el I.A.: The Journal of the Society for Industrial Archeology, en la colección "I.A.: Ways of Understanding, Ways of Being”, 2018. 


\section{De la experiencia personal a la colectiva: viajar en transporte público}

Crecí en Bogotá en los años 70, y experimenté los problemas de transporte público y movilidad derivados del flujo social, cultural y político de la ciudad. Las soluciones indicaban la construcción de un "metro": una infraestructura que, a pesar de diversos planes que se han proyectado desde hace 75 años (Roa 2016), nunca ha sido construida. A finales de los años 90 emigré a Barcelona con el deseo de una movilidad personal y profesional. La primera vez que viajé en el metro noté que la gente caminaba más rápido y sentí que de alguna manera esta tecnología controlaba sus movimientos. De alguna manera, y también por la extrañeza de la experiencia, le di la bienvenida a nuevas sensaciones de velocidad, movilidad y control, reflejando sentimientos de la "utopía" de viajar en tren, así como de “navegación y encarcelamiento" (De Certeau 1984, 111), una metáfora sugerida por De Certeau que "combina sueños con tecnología" (113). ${ }^{2}$ Los lugares parecían más cercanos de lo que pensaba, y la idea de tiempo era precisa y no diluida en la incertidumbre y el caos de mi ciudad natal. En un viaje de tren, vivía el efecto de "aniquilación del continuum tradicional de espacio tiempo que caracterizó la antigua tecnología de transporte" (Schivelbusch 1986, 36).

De manera simultánea, empecé a trabajar con tecnologías interactivas digitales y las entendí como el medio perfecto para representar la experiencia de viajar en el metro. Creé el $C D$ Rom Metro Interactivo ${ }^{3}$ (Figura 1), que evoca la experiencia del subterráneo, su movimiento, ritmo, sonido e imágenes. Pensé en extender este trabajo como un metro virtual en red que involucrara una perspectiva diversa de movilidad social y cultural.

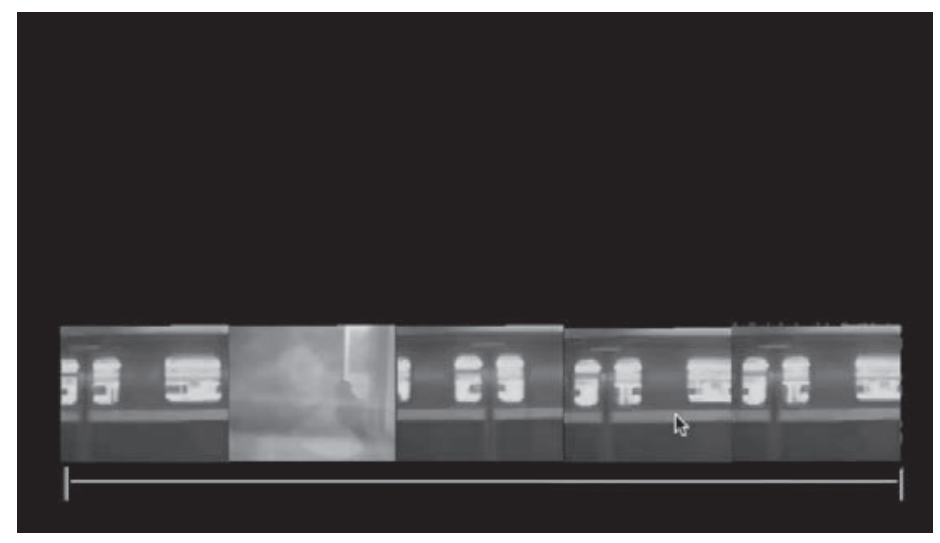

Figura 1 / Captura de pantalla de Metro Interactivo - Interactive Metro CD Rom (Foto tomada por la autora).

Años después, cuando llegué a Londres como extranjera, percibí el London Underground, ícono de la Revolución Industrial, como el espacio más familiar y emocionante (Figura 2). Inmersa en la acústica subterránea -su mezcla de sonidos reverberantes de máquinas y gente-, la experiencia produjo sentimientos de pertenencia; sentía asombro, excitación, empoderamiento y también soledad. Rosalind Williams dice que "el ambiente subterráneo es tecnológico - pero también es un paisaje mental, un terreno social y un mapa ideológico-".

2. De aquí en adelante todas las citaciones de autor son traducción propia del original en inglés.

3. Alarcón, Ximena. Interactive Metro - Metro Interactivo CD Rom, video demo, (October 17, 2012) https://vimeo. com/51626952. 
Ella sugiere que la sublimidad ${ }^{4}$ en espacios subterráneos "celebra ambivalencia” y depende del "delicado sobrepeso de emociones en conflicto" $(2008,21)$.

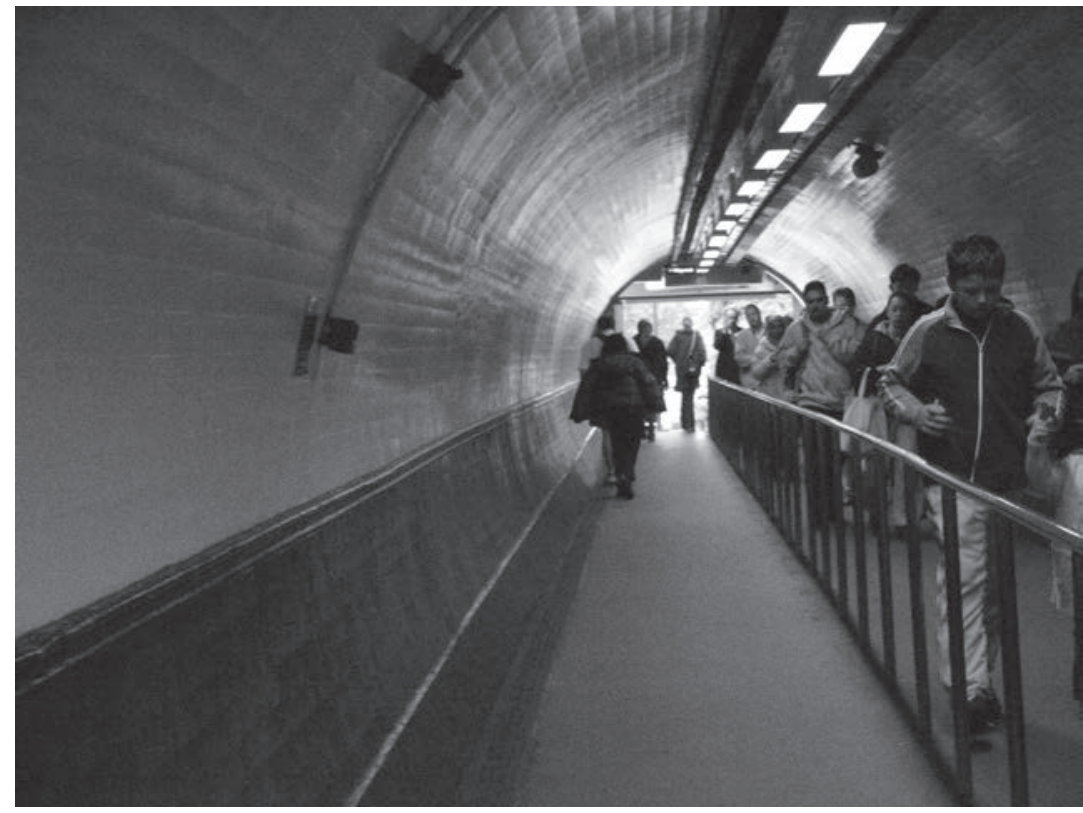

Figura 2 / Foto de la entrada al metro de Londres, Finsbury Park station (Foto tomada por la autora).

En una línea similar de pensamiento, Jean François Augoyard y Henry Torgue (2005) usan la palabra Sharawadji para describir un efecto sonoro que expresa lo sublime de la vida cotidiana: para alguna gente los "sonidos de tormenta originados tecnológica o industrialmente pueden sugerir una extrañeza preocupante y a la vez bella”, ritmos discontinuos, sonidos de alta intensidad y baja frecuencia en cualquier combinación pueden estimular este efecto, "la excepción invisible pero presente de lo ordinario" (119).

Cuando los viajes en metro se han convertido en rutina, me pregunto qué queda de la experiencia sonora en las memorias de los pasajeros y qué constituye una memoria colectiva aural.

\section{Memorias de pasajeros}

Entre 2004 y 2005 conduje una investigación sensorial etnográfica con veinticuatro pasajeros en Londres. Me enfoqué en la experiencia de escucha de cada pasajero a través de entrevistas, la grabación de sus viajes, y la selección de los eventos sonoros más significativos. Esta fue la base para crear el trabajo artístico en internet Interactive Sonic Environment: London Underground ${ }^{5}$ (Figura 3).

\footnotetext{
4. Lo "sublime" es entendido aquí desde la perspectiva filosófica de Edmund Burke (2013), como una percepción estética y exaltación proveniente de la experiencia con fenómenos naturales y otras experiencias extremas que causan una sensación casi visceral de placer, diferente a la experiencia estética de lo bello.

5. Alarcón, Ximena, Interactive Sonic Environment: London Underground, video demo, (5 de septiembre 2014) https:// vimeo.com/105343930.
} 


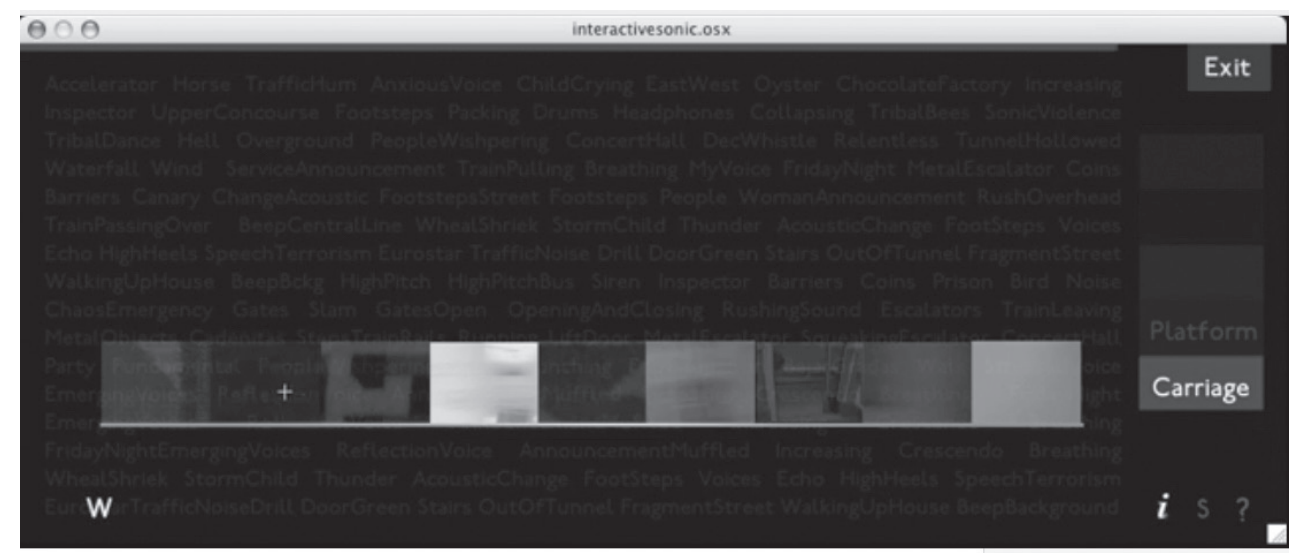

Figura 3 / Captura de pantalla de Interactive Sonic Environment: London Underground (Foto tomada por la autora).

En el 2007, extendiendo el método inicial y la práctica artística, realicé una investigación comparativa con las experiencias de escucha de pasajeros en los metros de París y Ciudad de México $^{6}$ (Figura 4) y como resultado creé Sounding Underground, ${ }^{7}$ un espacio sonoro interactivo que vincula las experiencias de los pasajeros en estas tres ciudades, invitando a la defamiliarización ${ }^{8}$ e interviniendo la linealidad del viaje en metro.

Tanto la infraestructura arquitectónica y tecnológica del sistema de transporte subterráneo, como también las tecnologías de redes digitales, se convirtieron para mí en "herramientas culturales" que nos permiten participar en un proceso de remembranza como una "acción mediada" (Wertsch 2002). La experiencia humana de viajar en metro subterráneo tiene algo intenso que nos invita a trascenderla.

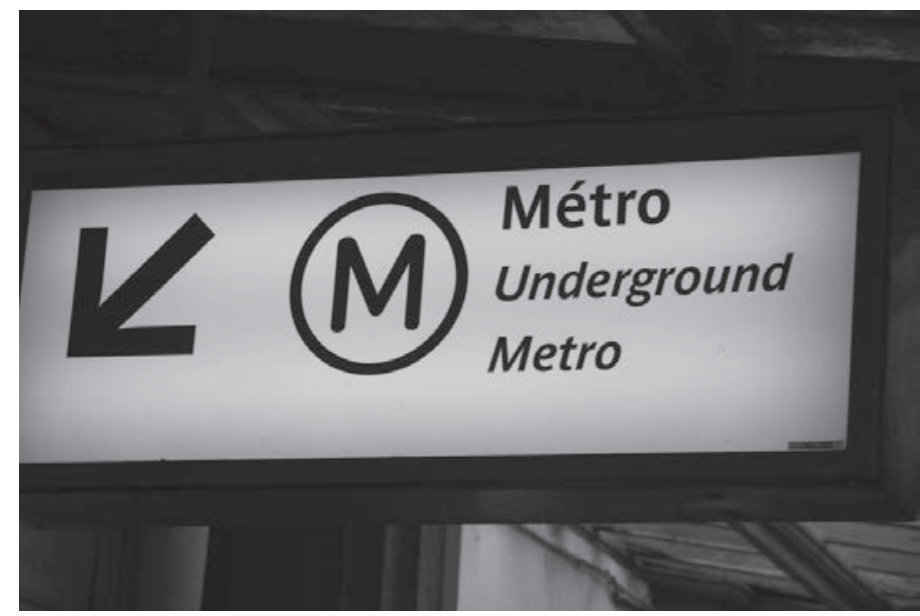

Figura 4 / Foto de aviso en tres lenguajes, metro de París (Foto tomada por la autora).

\footnotetext{
6. Dieciséis pasajeros del metro de México y dieciséis pasajeros del metro de París participaron en la investigación.

7. Alarcón, Ximena, Sounding Underground, Online Sonic Environment, (octubre 2009) http://soundingunderground. org

8. Defamiliarización es un concepto introducido por Viktor Shklovsky (1917) para describir una técnica artística que le ofrece al receptor de la obra la oportunidad de apreciar cosas comunes de una manera extraña o no familiar.
} 
Como si fuera un performance de la vida cotidiana, en Londres, Ciudad de México y París, las memorias de escucha de los pasajeros fueron más allá de la descripción de elementos sonoros externos; ellos expresaron sentimientos y metáforas que se referían a su cuerpo. Por lo tanto, en esta experiencia de viaje, el proceso de escuchar y recordar involucra al cuerpo humano como una interfaz explícita.

En este artículo resalto los afectos y emociones de los pasajeros, haciendo énfasis en los lazos que crea el cuerpo humano con la infraestructura tecnológica, y las interacciones y resonancias creadas con la voz. Describo cómo estas memorias son evocadas y transformadas en el ambiente virtual y sugiero cómo estas pueden expandir y trascender sentimientos contradictorios, derivados de la Revolución Industrial, hacia una percepción de movilidad que se expande en tiempo y espacio. Esta reflexión propone abrir preguntas sobre nuestra condición tecnológica, entendida en los términos de Erich Hörl (2015), como la relación entre "subjetividad y exterioridad" que constituye la pregunta ecológica general, "la cual es fundamentalmente renegociada en una base tecnológica" (10).

\section{Escucha en el cuerpo}

En uno de los mitos antiguos de ir por debajo de la tierra (Wolkstein y Kramer 1983), cuando la diosa Sumeria Innana decide visitar a su hermana Ereshkigal, la diosa del espacio subterráneo (the Great Below), ella "abre su oído" (xvii) al mundo subterráneo como un gesto que inicia el ritual de atravesar las siete puertas para encontrar a su hermana. Ella necesita abandonar "cielo y tierra", desligarse del espacio de arriba, incorporando un nuevo espacio. En el espacio subterráneo Williams nos recuerda que "la metáfora de profundidad es una categoría primaria del pensamiento humano", tal y como fue estudiado por Freud y Jung: "una experiencia edípica que divide al ser humano entre seres conscientes e inconscientes" (2008, 8). Refiriéndose al sonido, Augoyard y Torgue dicen que, "gracias a un sonido, un momento olvidado en nuestra vida es recuperado. No solo el sonido es recordado, sino que todos los otros componentes sensoriales y afectivos cruzan el umbral de la consciencia" $(2005,22)$. La práctica de Deep Listening desarrollada por Pauline Oliveros (2005) es una experiencia que nos permite acceder a esos espacios inconscientes, expandiendo nuestra percepción de tiempo y espacio a través del continuum sonoro, a través de la escucha del espacio que nos rodea, los sueños inconscientes (Lewis 2005) y el cuerpo (Gold 2008). Con referencia al cuerpo, Sharon Stewart (2012) se refiere al legado de Oliveros con el término "escucha somática", "la cual envuelve una escucha interna a las sensaciones y movimientos del cuerpo como también una escucha a todo el cuerpo, volviéndose esta altamente sensitiva a la energía kinésica (movimiento) del sonido del cual participa" (Stewart 2012). Es interesante notar cómo el nombre de esta práctica surgió por una experiencia sonora en un espacio subterráneo: una cisterna de veinte metros de profundidad donde Oliveros, junto con los músicos Panaiotis y Stuart Dempster, improvisaron musicalmente usando 45" de reverberación, cuyo efecto los sorprendió por darles la sensación de estar juntos, tocando música en el espacio, y al mismo tiempo percibiéndose cada uno con su sonido individual.

Interrelacionando las particularidades simbólicas, acústicas y perceptuales del espacio subterráneo, sugiero que la aniquilación de tiempo y espacio, experimentada históricamente con la tecnología de transporte, puede ser expandida a través de una escucha somática durante el viaje subterráneo: una experiencia intensa con reverberación, interacción con la maquinaria 
y la presencia de la multitud. En las tres ciudades estudiadas, los pasajeros expresaron formas de escucha somática de acuerdo con el movimiento experimentado en el viaje. Sus voces y las voces de otros, así como la cercanía con otros cuerpos -en la mayoría de los casos no deseada-, son también parte de esta interacción compleja.

\subsection{Sentados}

Es como un útero [risas]: es ir a tu estado primario [risas] y puedes desconectarte, es como muchos seres humanos yendo en un pequeño pod, y todos apretándose pero pretendiendo que no hay nadie más allí [...] y tienes ese ruido que te cubre, cuando viajas [...] llegas y te descomprimes para volver al mundo real (Alarcón Díaz 2007, 99). ${ }^{9}$

Esta percepción del Tube, ${ }^{10}$ nos recuerda el sentido del oído como el primero que se desarrolla en el útero de la madre (Truax 2001,33). Ser transportado con gente desconocida, y dejando el cuerpo a la suerte de la maquinaria, sugiere la creación de un lazo entre el cuerpo y el vagón, durante la navegación (Figura 5).

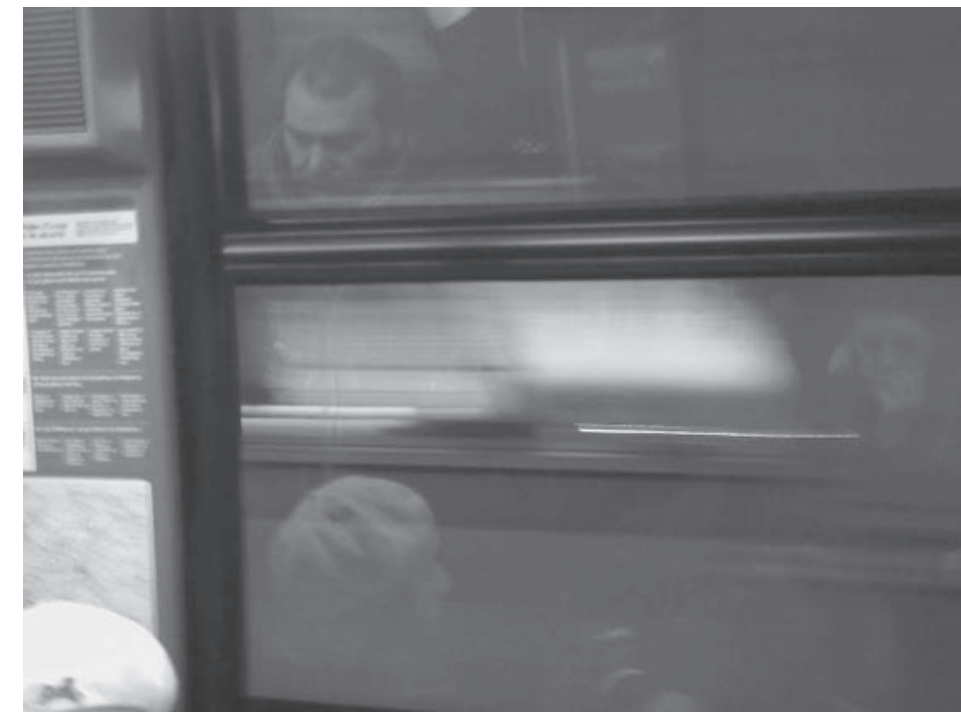

Figura 5 / Foto del metro de París, reflejo en la ventana (Foto tomada por la autora).

Por ejemplo, en Londres, Claudia ${ }^{11}$ dice que a su cuerpo no le gusta el movimiento del tren cuando este está suspendido; ella prefiere algo más suave como el Eurostar. Haciendo eco a Schivelbusch, sugiero aquí que aspectos históricos de mecanismos de suspensión son elementos importantes en esta navegación, como la metáfora de un tren "marco de huesos sin músculos” $(1986,116)$ que interactúa con el cuerpo. Aún más, pareciera que la profundidad del subterráneo evoca sentimientos de vínculos con un cuerpo más profundo que envuelve

\footnotetext{
9. Traducción propia del original en inglés
}

10. Como es llamado el metro en Londres.

11. Claudia Da Silva (pasajera Londres), entrevista con la autora, 15 de mayo 2004. Traducción propia del original en inglés. 
órganos vitales como el corazón y los pulmones. Por ejemplo, para Sofía el tren se convierte en "una extensión del cuerpo y cuando este se detiene es como si el cuerpo también se hubiera detenido"; ${ }^{12}$ el silencio consecuente, y la falta de movimiento, hacen de este momento un sentimiento cercano a la muerte. Ella siente un descanso cuando el sonido del motor vuelve y el tren lentamente retorna a su ritmo. Para Daniel, el sonido del aire expulsado por la puerta, "como un zumbido cuando para y expulsa el aire"13 en la última parada, hace que se prolongue y amplifique su respiración, recordando este sonido como una señal de alivio de haber llegado a casa.

En contraste, en México, donde la infraestructura es más moderna y nueva, y donde los trenes están más cercanos a la superficie, los pasajeros expresan un desapego de la maquinaria, y se enfocan en la presencia del aire:

Bueno, a mí lo que más me gustaba en la mañana, como todo el mundo va cansado o dormido, escuchas el aire, como a la velocidad que va el metro escuchas el aire, es muy relajante ese zumbidito de aire así, que nadie esté platicando, que impida esa tranquilidad. Porque incluso para cerrar las puertas, pues no te molesta, porque nada más vas escuchando el sonido del aire. ${ }^{14}$

Y también incorporan imaginación de espacios naturales, estimulada por el vaivén rítmico: "sí me podría imaginar el sonido del mar por el ritmo, el sonido del tren siempre tiene algo muy grato". ${ }^{15}$

En los testimonios de pasajeros en México se presenta una oposición al proceso mecánico del tren a través de la imaginación, expresando experiencias como la de Olga: "así como que me concentro y trato de sentir que el metro va para atrás". ${ }^{16}$ Estableciendo una definición clara entre máquinas y la humanidad, Álvaro observa este contraste en la rutina sonora del metro: "La misma gente, en la mañana es más efusiva dentro de las pláticas cuando va viajando, y en la tarde-noche pues viene obviamente agotada, cansada y es como más silenciosa. No sé, por otro lado las vías, las llantas al rechinar, estos sonidos que parecen ser -metafóricamente hablando- metálicos, no sé, como una especie de cuerpo dentro del cuerpo". ${ }^{77}$

Escuchar los distintos afectos, imaginaciones, metáforas y contrastes que el subterráneo produce en el cuerpo de los pasajeros me sugiere que la percepción de la maquinaria como parte del cuerpo humano gana intensidad cuando los pasajeros se sienten más lejanos de la superficie de la tierra, como en el caso de Londres, y, en contraste, en el caso de México se establecen más diferencias entre cuerpo y máquinas cuando los pasajeros se sienten más cerca de la superficie.

12. Sofía Buchuck (pasajera Londres), entrevista con la autora, 20 de mayo 2004. Traducción propia del original en inglés.

13. Daniel Ordoñez (pasajero Londres), entrevista con la autora, 20 de mayo 2004. Traducción propia del original en inglés.

14. Berenice García (pasajera México), entrevista con la autora, junio 2008.

15. Magali Tercero (pasajera México), entrevista con la autora, junio 2008.

16. Olga Cadena (pasajera México), entrevista con la autora, junio 2008.

17. Álvaro Itzama (pasajero México), entrevista con la autora, junio 2008. 


\subsection{Caminar y en quietud}

Las metáforas de "encarcelamiento y navegación” en el ferrocarril pueden ser percibidas, dentro de la infraestructura subterránea, a través de dos diferentes formas de movilidad: en los espacios en donde los pasajeros son transportados por máquinas -especialmente ascensores, escaleras eléctricas y trenes-y en los espacios donde ellos pueden caminar, como la plataforma y los corredores. Recordando al metro subterráneo como un ícono de la Revolución Industrial, considero importante notar aquí que el sentido del ritmo en la rutina laboral fue un gran cambio generado por esta revolución: mientras que los trabajadores anteriormente usaban aplausos y canto para acompañar sus rutinas, con la llegada de la industria sus rutinas se "desincronizaron" (Schafer 1994, 63). Por esta razón, creo que sensaciones extrañas durante la rutina de viaje no sorprenden cuando el cuerpo humano y las máquinas que lo transportan se encuentran.

Por ejemplo, en Londres, a Marco ${ }^{18}$ pasar las escaleras eléctricas le causa ansiedad, pues él no sabe si continuar su caminata o parar.

En los corredores, los pasos son esenciales para marcar el ritmo de la rutina y son percibidos como muy rápidos en Londres y muy lentos en México (Figura 6). Sin embargo, en los tres metros los pasos durante la hora pico se escuchan como un ejército marchando. La fuerza de los cuerpos en México crea conflicto, de alguna manera, con los procesos mecánicos. Por ejemplo, los pasajeros dicen que la gente no se mueve cuando viaja en las escaleras eléctricas, como sucede en París y Londres, para abrir un espacio de circulación. De la misma manera la multitud tiende a estar en las puertas del tren bloqueando la salida o entrada de más gente.

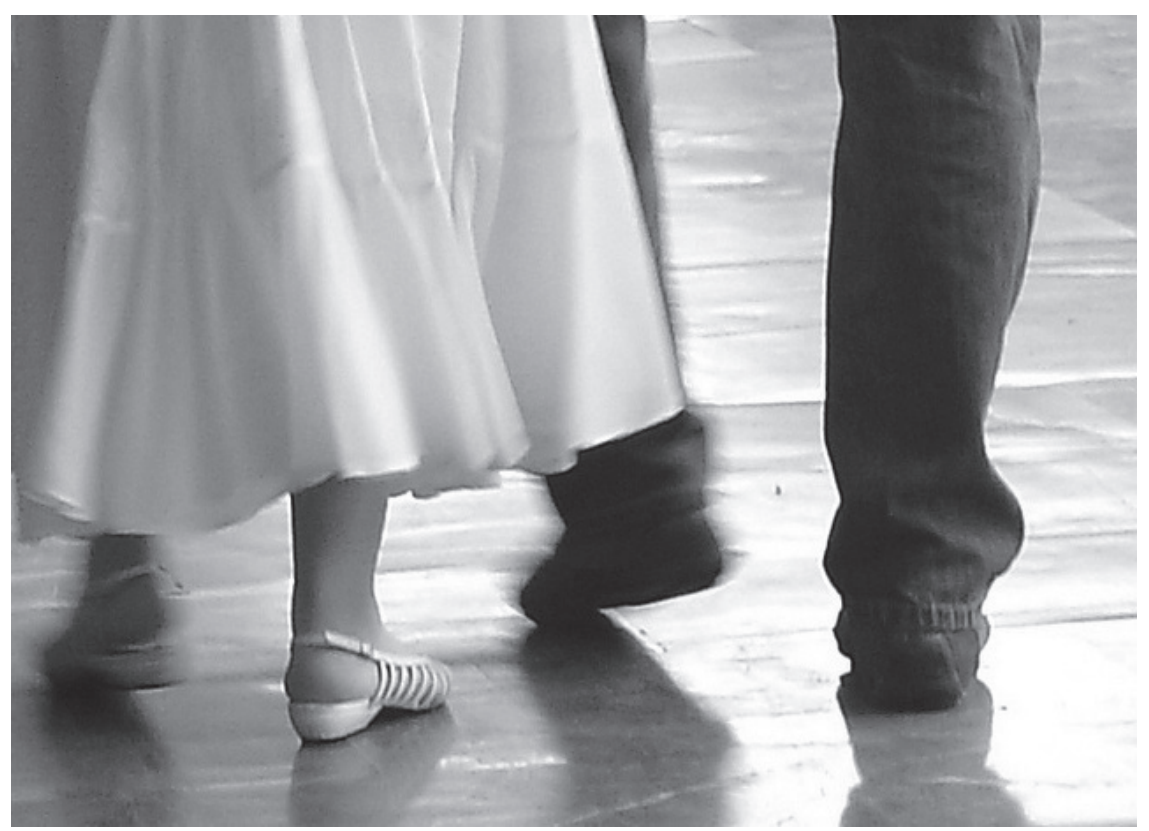

Figura 6 / Foto en el metro de México, detalle pasos (Foto tomada por la autora).

18. Marco Antonio Junqueira (pasajero Londres), entrevista con la autora, 21 de mayo 2004. Traducción propia del original en inglés. 
Como experiencia de liberación, Lorena en México, recuerda reaccionar frente al tren en la plataforma:

De hecho cuando era adolescente, cuando pasa el metro así me gustaba gritar en el metro. Como que me desahogaba, y como nadie me escuchaba, me hacía sentir bien, pues todos escuchaban un ruido pero no sabían que era yo. ${ }^{19}$

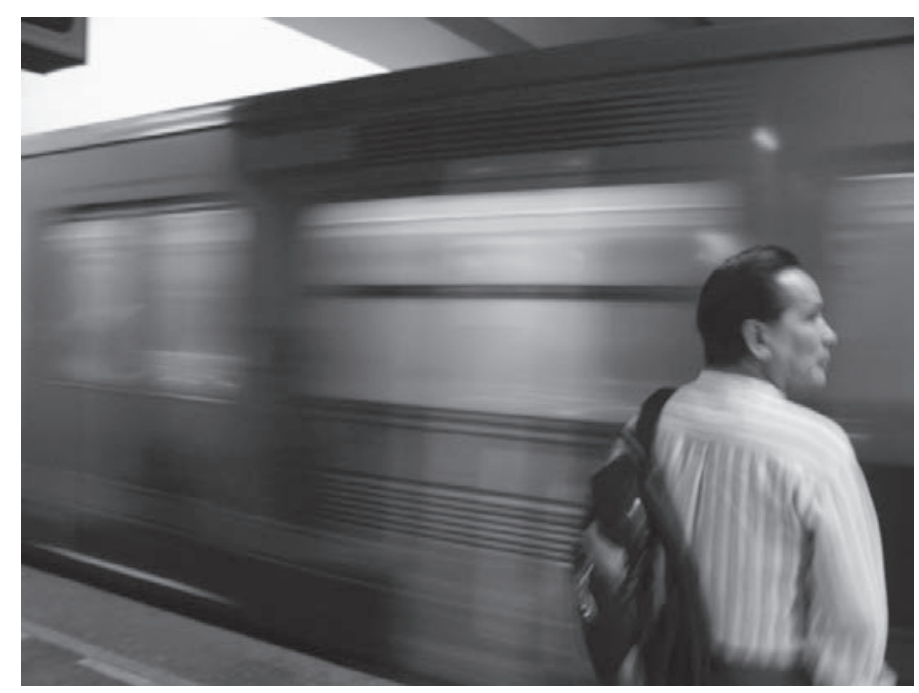

Figura 7 / Foto de pasajero esperando en la plataforma del metro de México (Foto tomada por la autora).

También en la plataforma, el metro actúa como un espacio intersticial (Figura 7). Entre salidas y llegadas los pasajeros entran en un nuevo mundo, el cual es metáfora de nuestro inconsciente. En su trabajo sobre los sueños, embodiment es descrito por Robert Bosnak como un fenómeno donde el soñador percibe el mundo como si fuera real, "presentándose él mismo como si fuera real, poblado por caracteres quienes despliegan sus propias intenciones, acompañadas por sensaciones físicas (latido del corazón, respiración), a veces lo suficientemente fuertes para hacerlos despertar" (Bosnak 2007, 9):

Era tarde, no había casi nadie en la plataforma y yo estaba sentada allí sola y de pronto apareció esa música muy distante flotando a través de los túneles, alguien estaba tocando, era música muy dulce, y después este hombre en la plataforma -al cual yo no le había prestado atención- arrastrando los pies al ritmo de la música, caminando a lo largo de la plataforma, de un lado al otro [...] 'shh $\mathrm{k}$ shh k shh k' así, y noté que él no tenía zapatos, tenía cartón amarrado a sus pies, vivía en la calle y era probablemente enfermo mental, y él estaba escuchando de manera atenta a la música. Y la música era muy dulce y él estaba muy loco y yo me sentí muy sola. ${ }^{20}$

Aquí hay una realización de un momento casi "sublime": la música como un ser, el hombre que danza la música y el producto emocional para la pasajera. Ella ha incorporado el placer y

19. Lorena Estrada (pasajera México), entrevista con la autora, junio 2008.

20. Claudia Da Silva, entrevista con la autora. Traducción propia del original en inglés (Alarcón Díaz 2007, 74). 
la tristeza de un subterráneo social, en lo que David Pike describe como una "ciudad vertical" $(2007,180)$, navegando como en un sueño, en la infraestructura arquitectónica y tecnológica.

\subsection{Voces}

Inmersos en el espacio reverberante, como si fuera un útero, sugiero que los pasajeros se conectan desde el vagón a "la voz y los sonidos hechos por humanos" (Truax 2001, 33), creando un sentido de conexión con otra gente, espacios y tiempos:

Trato de escuchar lo que ellos están diciendo y esto me recuerda mi hogar nativo, porque puedo imaginar que trato de escuchar a mi lenguaje de una manera informal, no es necesariamente que hay alguien quien quiere decirte algo, pero solo lenguaje informal como si fuera parte del paisaje. ${ }^{21}$

Escuchar casualmente voces de pasajeros, contrasta con la experiencia de escuchar voces incorpóreas de un subterráneo acústico como "una voz que rompe de su origen para volverse más grande, más poderosa y sugestiva, un sonido desligado de la tierra” (LaBelle 2010, 15).

Yo me asustaba con los parlantes y con voces que venían de lugares que no podía determinar. $^{22}$

Pienso que me está empezando a disgustar ese ángel que te dice el tiempo, las paradas y todo porque me siento como un robot, como que te dicen exactamente lo que debes hacer y especialmente las voces son de mando, como una autoridad allá afuera. ${ }^{23}$

Estas voces han sido grabadas con ciertas características culturales, como acentos, que son rechazados por los pasajeros, quienes se sienten mucho más a gusto con las voces de los conductores -voces amplificadas "en vivo"-, las cuales son más "humanas" y, por lo tanto, mantienen la espontaneidad de la vida cotidiana. Aunque en París los conductores y empleados del metro han grabado los anuncios, los pasajeros no recuerdan esta particularidad. Lo que ellos recuerdan con más aprecio es la música tocada por músicos callejeros en el metro (Figura 8). En México, principalmente vendedores ambulantes crean una "voz amplificada" usando una técnica vocal desarrollada para ese espacio en particular y tocando música a través de parlantes que se sujetan a sus morrales (Figura 9), constituyendo una característica clásica del sonido del metro. Los vendedores hablan en un "tono más alto que el usual", ${ }^{24}$ compitiendo de alguna forma con el sonido del tren y su velocidad.

21. Mónica Acosta, entrevista con la autora. Traducción propia del original en inglés (Alarcón Díaz 2007, 99).

22. Richard Souray (pasajero Londres), entrevista con la autora, 23 de junio 2004. Traducción propia del original en inglés.

23. Sofía Buchuck (pasajera Londres), entrevista con la autora, 20 de mayo 2004. Traducción propia del original en inglés.

24. Oscar Díaz (pasajero México), entrevista con la autora, junio 2008. 


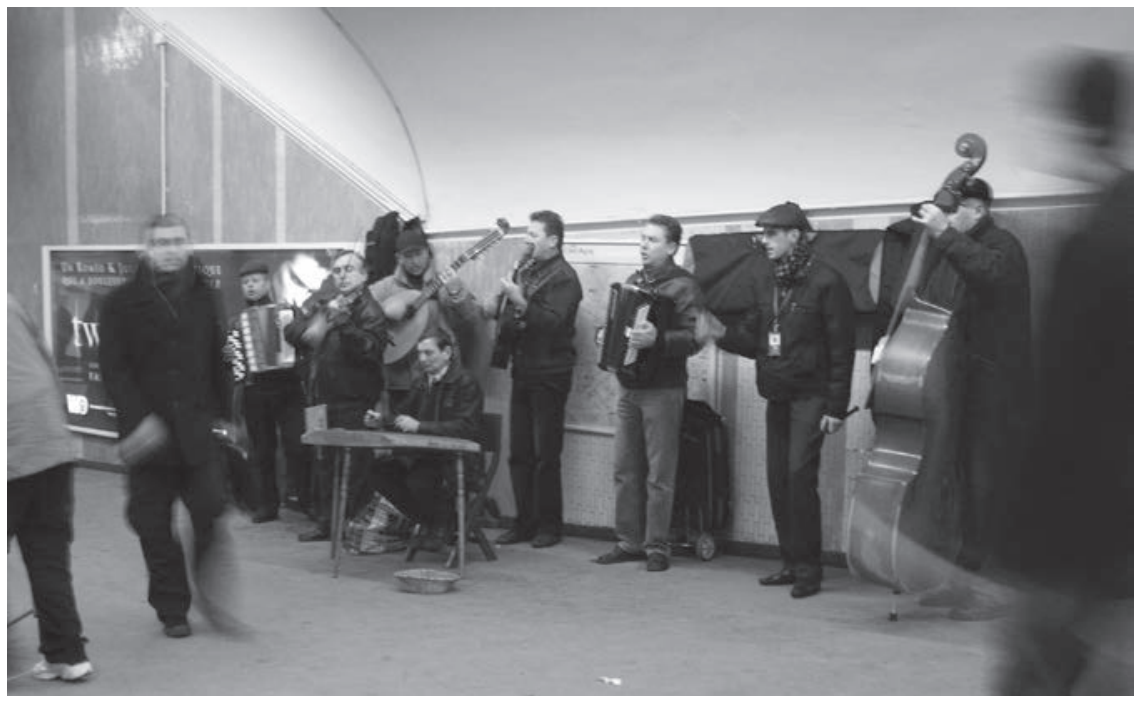

Figura 8 / Cantantes ambulantes en el metro de París (Foto tomada por la autora).

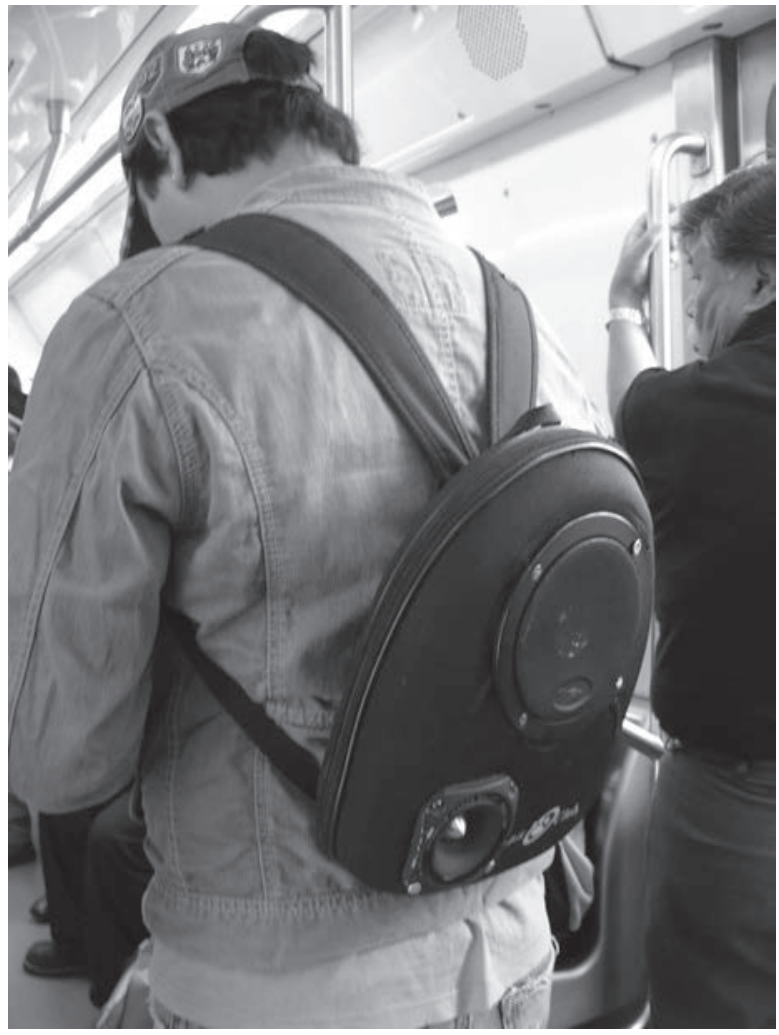

Figura 9 / Vendedor de música en el metro de México (Foto tomada por la autora).

He llamado a este espacio acústico que se vive con diferentes voces, en los tres metros, "voz amplificada". Sus contrastes muestran expresiones del cuerpo donde el control y la liberación se sienten como poderes sociales e institucionales entremezclados. 


\subsection{Proximidad con otros}

En el metro de París, la proximidad obligada con otros se percibe de manera intensa:

Cuando estás en el metro tú no eres tú mismo... estás forzado a aceptar a la gente... cada uno es una burbuja íntima como un área de ti mismo... Entonces para mí este hecho significa que... en el metro no estás seguro... ${ }^{25}$

En Ciudad de México los pasajeros expresan miedos de perder su individualidad:

Somos tantos que no te importa si estás de pie y hay un codo de un hombre aquí, en tu cara, o si de repente estás casi besando a la mujer de en frente porque está completamente lleno [...] la gente pierde su individualidad, te comportas como una masa. ${ }^{26}$

Allí, para las mujeres, la burbuja de intimidad se rompe, y por esta razón hay tres vagones para mujeres y niños:

Y de pronto estamos solo mujeres dentro del vagón; la idea es protegernos de los hombres. Luego, el sonido es muy bonito. Me gusta porque es el tipo de conversación entre mujeres, que es más íntima, pausada, no hay competencia porque no hay hombres... generalmente son conversaciones de amigas... las voces son más moduladas, bajas, todo es más sereno. ${ }^{27}$

La percepción del Tube como una membrana uterina, la conexión con otros, la experiencia de lo sublime, las tensiones producidas por el control de las máquinas (incluidos los parlantes) y la cercanía física con otros, son ejemplos de sensaciones que involucran al cuerpo intensamente en la experiencia de viaje en metro todos los días en los tres sistemas subterráneos de transporte. La escucha somática sugiere una combinación de sentimientos que derivan de percepciones directamente relacionadas con el cuerpo, máquinas y también con percepciones sociales. ¿Qué pasa con estas percepciones cuando la experiencia sonora del metro se vuelve virtual? -en otras palabras, desincorporada de la infraestructura de las máquinas y de otros humanos, y mediada por tecnología digital-.

\section{Disembodied Sounding Underground}

Las experiencias de pasajeros en los tres metros informaron la creación de Sounding Underground (Alarcón 2013). Los movimientos que los pasajeros realizan para completar su rutina fueron el foco principal para crear la estructura del metro virtual que vincula sonidos seleccionados por los pasajeros de sus viajes en los tres metros. Una notación sónica se convirtió en la interface digital que entretejió sus experiencias de escucha. La notación fue compuesta usando cinco espacios comunes del viaje en cada ciudad: entrada, tiquetes, corredor, plataforma y vagón de tren (Figuras 10, 11 y 12). Cada uno de estos espacios contiene "categorías", que incluyen: sonidos relacionados con el espacio donde estos suceden (i.e. escaleras), sonidos producidos

25. Nicolas Perrin (pasajero París), entrevista con la autora, enero 2009. Traducción propia del original en inglés.

26. Daniel Gutiérrez (pasajero México), entrevista con la autora, junio 2008.

27. Magali Tercero (pasajera México), entrevista con la autora, junio 2008. 
por la maquinaria de los trenes y sus acciones (i.e. puertas que se abren), y también sonidos que están contenidos en espacios poéticos que reflejan los sentimientos de los pasajeros (i.e. je respire - yo respiro). Cada metro también tiene un espacio único sonoro, ${ }^{28} \mathrm{y}$ los tres metros tienen cuatro espacios sonoros compartidos tales como puertas, trenes que llegan, pasos y voces amplificadas. En estos espacios se ubica el mayor número de selecciones de sonidos por parte de los pasajeros a lo largo de todos sus viajes, evidenciando la importancia otorgada a estos en sus memorias sonoras. La interface entrelaza todos los sonidos, que se activan de manera aleatoria cuando el visitante en internet interactúa, percibiendo el contrapunto de la experiencia sónica urbana contemporánea.

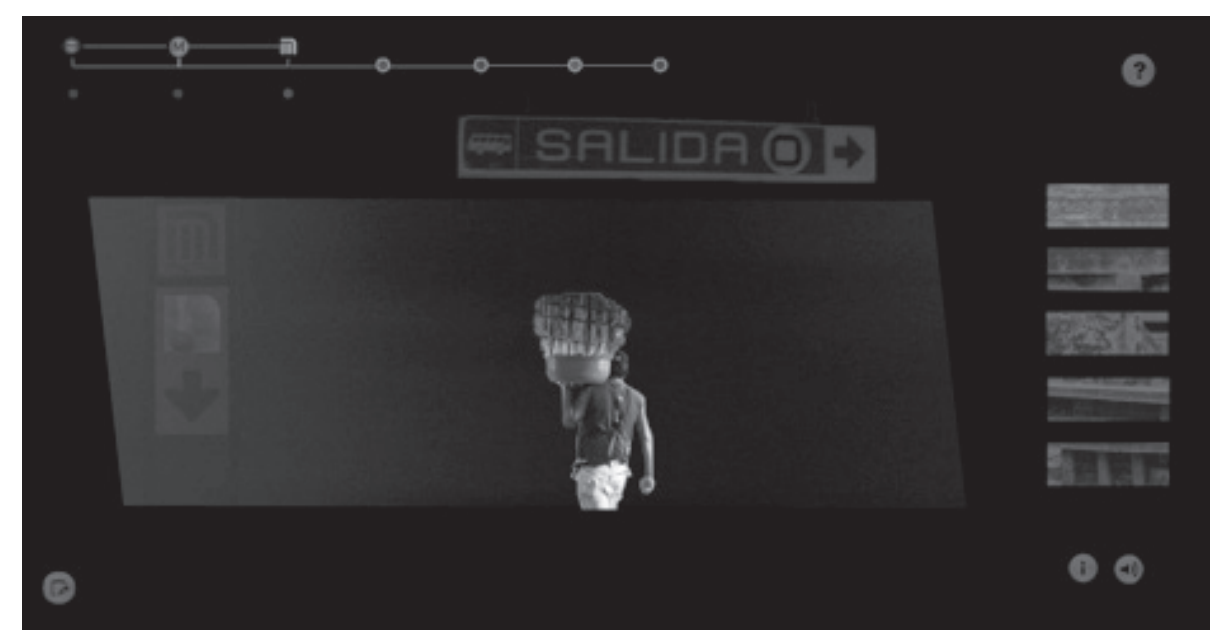

Figura 10 / Captura de pantalla metro de México -“Entrada” en Sounding Underground (Foto tomada por la autora).

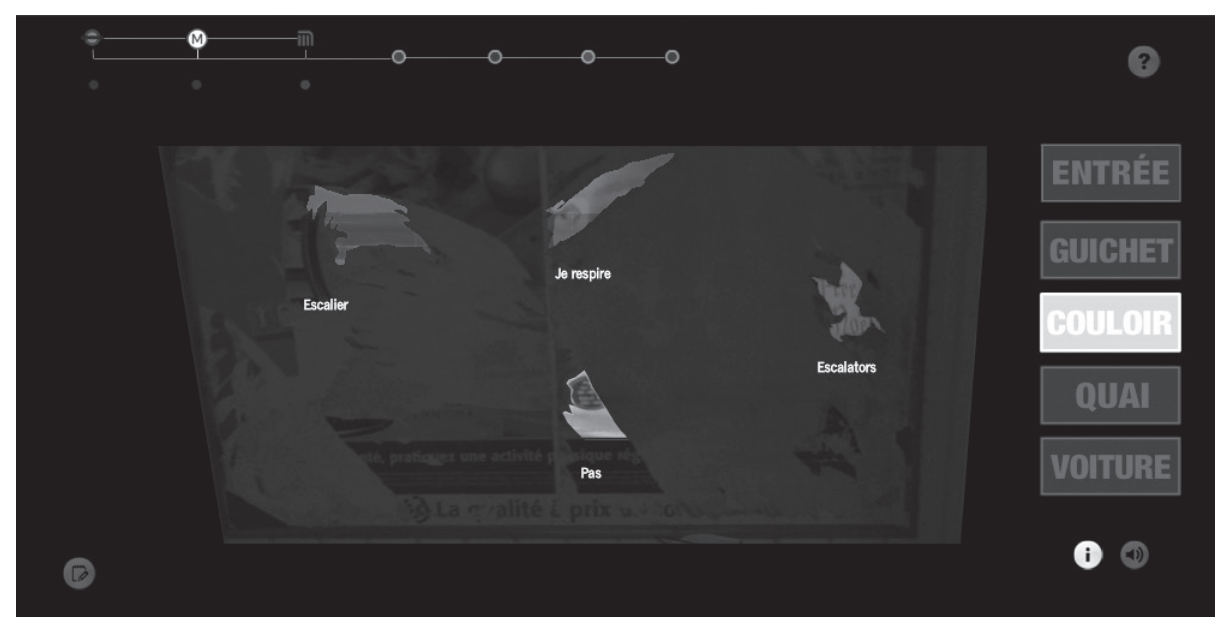

Figura 11 / Captura de pantalla metro de París -“Corredores" en Sounding Underground (Foto tomada por la autora).

28. Como el de los anuncios en Londres, los vendedores ambulantes en México y los sonidos de aire expulsado con fuerza por trenes y puertas en París. 


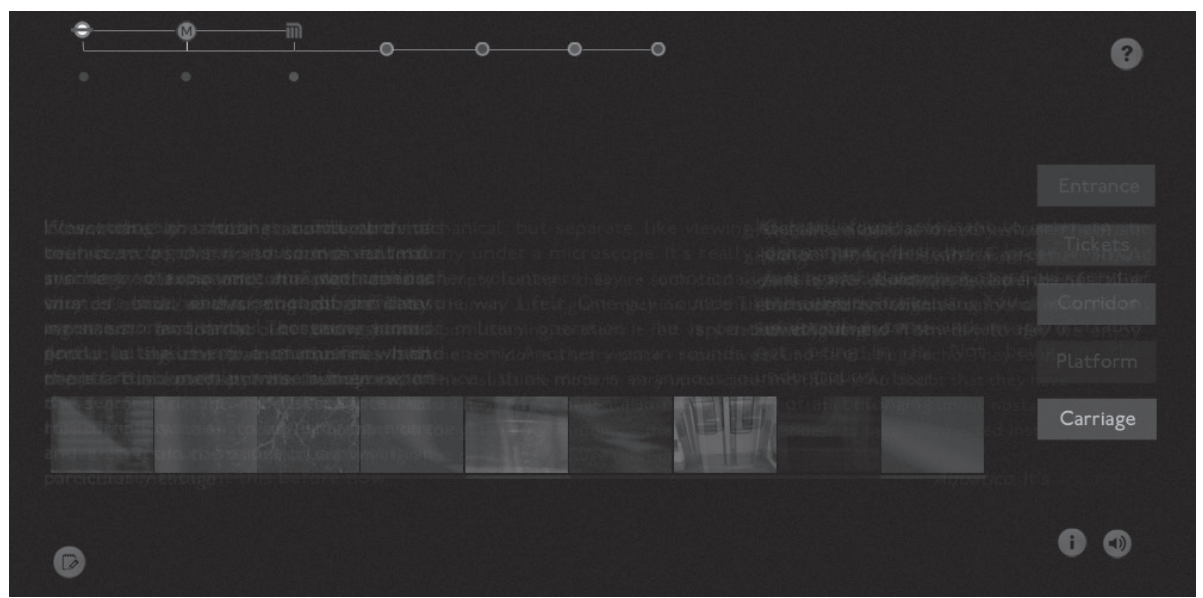

Figura 12 / Captura de pantalla metro de Londres -“Vagón" en Sounding Underground (Foto tomada por la autora).

La sensación somática o embodiment en espacios virtuales ha sido estudiada por investigadoras de tecnologías de performance como Chatzichristoudolou y Zerihan (2012), a través del análisis de trabajos artísticos que involucran encuentros remotos entre personas a través de tecnologías en red que pueden "mejorar la cercanía”. Discusiones sobre trabajos artísticos en un evento llamado Intimacy las llevan a argumentar que "tecnologías de intersubjetividad generan heterotopías, ${ }^{29}$ las cuales pueden funcionar como los escenarios para bellos, pero también amenazadores encuentros" (2012,3). Estos encuentros podrían contrastar y también establecer paralelos con los que suceden en los metros físicos, que involucran sentimientos de privacidad, atracción y rechazo respecto a los que están cerca físicamente. Estos sentimientos contradictorios hacen eco a la sublimidad de los espacios subterráneos y se vuelven un punto interesante para pensar a Sounding Underground como un espacio virtual de encuentros performativos "en el borde entre intervención sónica y performance (por no-músicos)". ${ }^{30}$

Cuando escuchan el metro virtual, los visitantes en línea experimentan sensaciones somáticas, recordando la experiencia física y trascendiendo aún más la percepción de sí mismos y del otro:

Es el acento del mundo condensado en una experiencia sintetizada haciendo humano lo que siempre pensé era una experiencia mecánica y más bien un espacio alien. Y en una corriente de consciencia me encuentro acolchonada por el efecto de ruido-blanco del Tube rodeado y reafirmado por las voces. Pero las voces no son afectadas o forzadas a tener un mensaje en particular. ${ }^{31}$

29. Heterotopías es un concepto desarrollado por Michel Foucault (1967) para describir lugares que actúan como contralugares: "una especie de utopía efectivamente representada en la cual los sitios reales, todos los otros sitios reales que se pueden encontrar dentro de la cultura, son simultáneamente representados, controvertidos e invertidos”.

30. Carole Chargueron, mensaje electrónico a la autora, 6 de enero de 2010.

31. Lesley Larkum, Agosto, 2005, comentario en "Interactive Environment London Underground", Listening and Remembering (blog). Traducción propia del original en inglés. Acceso: 28 de febrero 2017. http://soundingunderground. org/listeningtexts/alien.html. 
Igualmente, Sounding Underground crea una experiencia contrastante del subterráneo, la cual trasciende experiencias específicas de ciudad, o el sentido de tener un destino:

Tanto más estuve allí, tanto más pude sentir los espacios y la conectividad de las tres ciudades como una vasta red subterránea. [...] Me encantó el sonido del tren que es como el de la respiración, el tren neumático. Me encantaron los diferentes idiomas y la similitud jocosa de los anuncios. [...] Fue maravilloso disfrutar la belleza del metro sin la ansiedad de encontrar mi ruta y correr, la abrumadora multitud, o el cansancio de las escaleras y corredores interminables. A veces, yo me sorprendí estando en un lugar en el que no sabía a donde iba y esto fue maravilloso. ${ }^{32}$

El próximo mes voy a Ciudad de México por primera vez, sola, no conozco a nadie y me siento un poco asustada de la magnitud y la multitud. Escuchar los sonidos que escucharé allí me ha relajado. Sé que me acercaré a la ciudad de manera más creativa ahora por la manera en que me la has "presentado". ${ }^{33}$

Empecé a inventarme historias sobre ellos y sus viajes mientras recordaba mis propios viajes a través de los metros de NY y París. Hay algo sobre el movimiento que da una clase de libertad de pensamiento, ¿̇no ${ }^{34}$

Creo, entonces, que el cuerpo se libera de su concha de viaje y puede tener la experiencia de escuchar todas las sutilezas del sonido. El computador es una ventana liberadora, que expande el espacio. El sonido es percibido por el cuerpo en quietud escuchando el viaje entero como si este fuera un sueño:

Desde hace días vengo conociendo tu espectacular trabajo... con algunas interrupciones. He explorado poco a poco... y cada vez descubro más detalles y cosas interesantes... mis sentimientos hasta el momento son de transportación a lugares desconocidos y a la sensación de que en cada lugar, de acuerdo a su cultura y las diferentes ciudades, la gente vive de un modo muy diferente... siente diferente... afronta diferente... qué sé yo... estoy tratando de meter algunas memorias... ya lo sabrás... ${ }^{35}$

Por lo tanto, sentimientos de "navegación y encarcelamiento" se tornan casi una experiencia de sueño lúcido donde no hay límites. La escucha a través de auriculares, ${ }^{36}$ asemejada a la escucha a través de la membrana uterina, se hace más íntima en el encuentro con otros en locaciones distantes. Tener encuentros con una experiencia abstraída del espacio industrial, sin la necesidad de tener un destino, sino una experiencia ambulante en el espacio virtual, puede trascender las ideas predeterminadas y fijas sobre los lugares físicos.

32. Andrea Goodman, mensaje electrónico a la autora. Traducción propia del original en inglés. 14 de noviembre 2009.

33. Jo Stanley, mensaje electrónico a la autora. Traducción propia del original en inglés. 17 de diciembre 2009.

34. Taryn FitzGerald, mensaje electrónico a la autora. Traducción propia del original en inglés. 8 de enero 2011.

35. María Gabriela Alarcón, mensaje electrónico a la autora, 11 de diciembre 2011.

36. De las grabaciones que fueron hechas con micrófonos binaurales, en el caso de México y París. 


\section{Conclusiones}

Sugiero que, en el ritual de ir por debajo de la tierra, los pasajeros se desincorporan de la superficie, y después, al escuchar, ellos experimentan somatizaciones como formas de recordar. La defamiliarización que se produce a través del trabajo artístico digital Sounding Underground, amplía el significado de un espacio que ha sido incorporado (embodied), encontrando nuevas percepciones, evocando sentimientos de "sublimidad" característicos de espacios subterráneos físicos sonoros.

Podría decir que los visitantes a Sounding Underground han dejado sus cuerpos, a través de sus oídos, a la imaginación que se deriva de una realidad no muy distante. Sin embargo, en este viaje la interacción es ofrecida en una nueva máquina de viaje: el computador. Establecer conexiones entre la red de ferrocarriles subterránea y el espacio en red de Internet, nos invita a pensar en retos de navegación virtual donde el cuerpo está generalmente en quietud.

Haciendo eco a las relaciones entre "sueños y tecnología", sugeridas por De Certeau, derivadas de la experiencia de viajar en ferrocarril, también sugiero que esta relación física-virtual-física creada a través de Sounding Underground se acerca a una experiencia de escucha profunda (de acuerdo con la práctica y filosofía de Pauline Oliveros), por las sensaciones incorporadas y por la experiencia porosa de los sueños. Las metáforas de "navegación y encarcelamiento" asociadas a la utopía del viaje en tren contrastan con la heterotopía de los encuentros performativos en espacios virtuales.

La percepción del metro subterráneo como una membrana uterina, la conexión provocada con otros que están cerca y distantes, y la experiencia de lo sublime en el metro físico y virtual, sugieren una experiencia de movilidad en espacios "intermedios", como una reflexión iterativa entre los dos espacios. Propongo escuchar de manera "intermedia" espacios subterráneos físicos y virtuales como práctica que expande la experiencia del cuerpo dentro del continuum sonoro de tiempo y espacio, reclamando movilidad y abriendo un camino para la trascendencia de nuestra condición tecnológica (Hörl): la pregunta ecológica entre subjetividad y exterioridad que se negocia con las infraestructuras tecnológicas.

\section{Referencias}

Alarcón Díaz, Ximena. 2007. "An Interactive Sonic Environment derived from commuters' memories of soundscape: a case study of the London Underground". Tesis de Doctorado, De Montfort University.

Alarcón, Ximena. 1998. "Interactive Metro - Metro Interactivo". Online video demo de CD Rom original. https://vimeo.com/51626952 . Acceso: 31 de enero de 2018.

2013. “Creating Sounding Underground”. Digital Creativity Journal 24 (3): 252-258.

Augoyard, Jean Françoise y Torgue Henry, eds. 2005. Sonic Experience. A Guide to Everyday Sounds. Traducción de Andra McCartney y David Paquette. Montreal: McGill-Queen's University Press. 
Bosnak, Robert. 2007. Embodiment: Creative Imagination in Medicine, Art and Travel. East Sussex: Routledge.

Burke, Edmund. 1860. A Philosophical Inquiry into the Origin of Our Ideas of the Sublime and Beautiful: With an Introductory Discourse Concerning Taste. New York: Harper \& Brothers.

Chatzichristodoulou, Maria y Rachel Zerihan. 2012. Intimacy Across Visceral and Digital Performance. Basingstoke: Palgrave Macmillan.

De Certeau, Michel. 1984. The Practice of Everyday Life. Berkeley, CA: University of California Press.

Foucault, Michel. 1967. Of Other Spaces: Utopias and Heterotopias. http://web.mit.edu/ allanmc/www/foucault1.pdf. Acceso: 24 de mayo de 2018.

Gold, Heloise. 2008. Deeply Listening Body. Kingston, NY: Deep Listening Publications.

Hörl, Erich. 2015. “The Technological Condition”. Traducción de Anthony Enns. PARRHESIA: A Journal of Critical Philosophy 22: 1-15.

LaBelle, Brandon. 2010. Acoustic Territories. London: Continuum International Publishing Group Ltd.

Lewis, Carole Ione. 2005. Listening in Dreams. Lincoln, NE: iUniverse Books.

Roa, Oscar Alfonso. 2016. “¿Por qué Bogotá no tiene al menos una línea metro? Y las razones por las que probablemente no la tendrá”. OPERA 19: 139-159.

Oliveros, Pauline. 2005. Deep Listening: A Composer's Sound Practice. Lincoln, NE: iUniverse Books.

2010. Sounding the Margins. Collected writings 1992-2009. Kingston NY: Deep Listening Publications.

Pike, David L. 2007. Metropolis in the Styx. The Underworlds of Modern Urban Culture, 18002001. Ithaca, NY: Cornell University Press.

Schafer, R. Murray. 1994. The Soundscape: Our Sonic Environment and the Tuning of the World. Rochester, Vermont: Destiny Books.

Schivelbusch, Wolfgang. 1986. The Railway Journey. The Industrialization of Time and Space in the Nineteenth Century. Berkeley, CA: The University of California Press.

Stewart, Sharon. 2012. "Listening to Deep Listening". Journal of Sonic Studies 2 (1).

Shklovsky, Viktor. 1917. "Art as Technique”. https://paradise.caltech.edu/ist4/lectures/ Viktor_Sklovski_Art_as_Technique.pdf. Acceso: 24 de mayo de 2018. 
Truax, Barry. 2001. Acoustic Communication. Westport, CT: Ablex.

Williams, Rosalind H. 2008. Notes on the Underground: An Essay on Technology, Society and the Imagination. Cambridge, MA: MIT Press.

Wertsch, James. 2002. Voices of Collective Remembering. Cambridge: Cambridge University Press.

Wolkstein, Diane y Samuel Noah Kramer. 1983. Innana: Queen of Heaven and Earth. New York: Harper \& Row Publishers Inc. 